\section{The role of high-flow nasal cannula therapy in patients with respiratory failure}

In a meta-analysis published in CMAJ, Ou and colleagues reported that, compared with use of conventional oxygen therapy, use of high-flow nasal cannula oxygen therapy could reduce the intubation rate in patients with acute hypoxemic respiratory failure. ${ }^{1}$ Although this study was welldesigned, we identified several issues.

First, a search bias possibly existed, as 6 more trials were identified in our recent literature search (conducted September 2018)..$^{2-7}$ However, in our meta-analysis that included these additional trials (unpublished data, 2018), ${ }^{2-11}$ the conclusion remained consistent with that of Ou and colleagues.

Second, in our meta-analysis, the range of intubation rates was very large within these trials (from $0 \%$ in the study by Rittayamai and colleagues, ${ }^{7}$ to $42 \%$ in the study by Frat and colleagues ${ }^{8}$ ), indicating potential heterogeneity among these studies. Several well-designed studies ${ }^{8}$ and the trial by Hernández and colleagues ${ }^{9}$ also showed inconsistent findings.

Furthermore, we noticed that the severity of respiratory failure $\left(\mathrm{PaO}_{2}: \mathrm{FiO}_{2}\right)$ at baseline differed among trials. Thus, we performed a subgroup meta-analysis to investigate whether the conclusion stayed consistent depending on $\mathrm{PaO}_{2}: \mathrm{FiO}_{2}$ levels. We divided the included trials into 3 subgroups according to the $\mathrm{PaO}_{2}$ : $\mathrm{FiO}_{2}$ at enrolment
( $\geq 200,<200$ and unreported). In the subgroup with high $\mathrm{PaO}_{2}: \mathrm{FiO}_{2},{ }^{3,6,9,10}$ use of highflow nasal cannula oxygen therapy had a significant reduction in the intubation rate compared with use of conventional oxygen therapy. However, in the subgroup with low $\mathrm{PaO}_{2}: \mathrm{FiO}_{2},{ }^{5,8}$ this benefit of high-flow nasal cannula oxygen therapy was nonsignificant.

Despite increased evidence supporting the use of high-flow nasal cannula oxygen therapy in acute respiratory failure, its inappropriate application may cause necessary intubation to be delayed, which is associated with poor outcomes. ${ }^{12}$ Thus, we suggest further studies are still needed to evaluate the benefit of high-flow nasal cannula oxygen therapy in patients with severe respiratory failure.

\section{Xuping Cheng MD}

Intensivist, Dongyang People's Hospital, Jinhua, Zhejiang, China

\section{Weimin Zhang MD}

Intensivist, Dongyang People's Hospital, Jinhua, Zhejiang, China

Cite as: CMAJ 2019 January 14;191:E53. doi: $10.1503 / \mathrm{cmaj} .71024$

\section{References}

1. Ou X, Hua Y, Liu J, et al. Effect of high-flow nasal cannula oxygen therapy in adults with acute hypoxemic respiratory failure: a meta-analysis of randomized controlled trials. CMAJ 2017;189:E260-7.

2. Bell N, Hutchinson CL, Green TC, et al. Randomised control trial of humidified high flow nasal cannulae versus standard oxygen in the emergency department. Emerg Med Australas 2015;27:537-41.
3. Corley A, Bull T, Spooner AJ, et al. Direct extubation onto high-flow nasal cannulae post-cardiac surgery versus standard treatment in patients with a $\mathrm{BMI} \geq 30$ : a randomised controlled trial. Intensive Care Med 2015;41:887-94.

4. Jones PG, Kamona S, Doran O, et al. Randomized controlled Trial of humidified high-flow nasal oxygen for acute respiratory distress in the emergency department: the HOT-ER Study. Respir Care 2016;61:291-9.

5. Lemiale V, Mokart D, Mayaux J, et al. The effects of a 2-h trial of high-flow oxygen by nasal cannula versus Venturi mask in immunocompromised patients with hypoxemic acute respiratory failure: a multicenter randomized trial. Crit Care 2015;19:380.

6. Parke R, McGuinness S, Dixon R, et al. Openlabel, phase II study of routine high-flow nasal oxygen therapy in cardiac surgical patients. $\mathrm{Br} \mathrm{J}$ Anaesth 2013;111:925-31.

7. Rittayamai N, Tscheikuna J, Praphruetkit N, et al. Use of high-flow nasal cannula for acute dyspnea and hypoxemia in the emergency department. Respir Care 2015;60:1377-82.

8. Frat JP, Thille AW, Mercat A, et al.; FLORALI Study Group; REVA Network. High-flow oxygen through nasal cannula in acute hypoxemic respiratory failure. N Engl J Med 2015;372:2185-96.

9. Hernández G, Vaquero C, González P, et al. Effect of postextubation high-flow nasal cannula vs conventional oxygen therapy on reintubation in low-risk patients: a randomized clinical trial. JAMA 2016;315:1354-61.

10. Maggiore SM, Idone FA, Vaschetto R, et al. Nasal high-flow versus Venturi mask oxygen therapy after extubation. Effects on oxygenation, comfort, and clinical outcome. Am J Respir Crit Care Med 2014;190:282-8.

11. Perbet SGA, Chabanne R. High-flow nasal oxygen cannula versus conventional oxygen therapy to prevent postextubation lung aeration loss: a multicentric randomized control lung ultrasound study. Intensive Care Med 2014;40(Suppl 1):S128.

12. Kang BJ, Koh Y, Lim CM, et al. Failure of highflow nasal cannula therapy may delay intubation and increase mortality. Intensive Care Med 2015; 41:623-32.

Competing interests: None declared. 